\title{
Use of Mitomycin C for Refractory Esophageal Stricture following Tracheoesophageal Fistula Repair
}

\author{
Anna Lakoma ${ }^{1}$ Sara C. Fallon ${ }^{1}$ Shawn Mathur ${ }^{1}$ Eugene S. Kim ${ }^{1}$ \\ ${ }^{1}$ Division of Pediatric Surgery, Michael E. DeBakey Department of \\ Surgery, Baylor College of Medicine, Houston, Texas, United States \\ Address for correspondence Eugene S. Kim, MD, CCC Building, Suite \\ 1210, 6701 Fannin, Houston, TX 77030, United States \\ (e-mail: eskim@bcm.edu). \\ Eur J Pediatr Surg Rep 2013;1:24-26.
}
Abstract
Keywords
- mitomycin C
- esophageal stricture
- tracheoesophageal
fistula

Esophageal stricture is a well-described complication following tracheoesophageal fistula repair. Herein, we report two patients who had persistent esophageal strictures after several months of repeat balloon dilatations. Each patient was treated with a single application of topical mitomycin $\mathrm{C}$ in addition to esophageal dilatation, which resulted in complete resolution of the stricture.

\section{Introduction}

Tracheoesophageal fistulas (TEFs) are treated with operative ligation of the distal fistula and anastomosis of the esophageal limbs. The development of an esophageal stricture at the anastomosis is a well-described complication after repair, occurring in approximately one-third of patients. ${ }^{1}$ Endoscopic balloon dilatation is currently the preferred method of treatment for both initial and recurrent esophageal strictures. Recently, the use of topical mitomycin C (MMC) for the treatment of esophageal strictures after surgical repair and caustic injury has been reported. In these studies, MMC treatment was largely successful in the resolution of esophageal strictures with a minimal complication profile. ${ }^{2,3}$ However, the vast majority of the reported cases of MMC use in esophageal strictures have been secondary to caustic injury, with a paucity of reported cases after newborn TEF repair. Herein, we report the successful use of topical MMC in combination with balloon dilatation for the treatment of refractory esophageal strictures following TEF repair in two neonates with complete resolution of the stricture without complications.

\section{Case Reports}

\section{Case 1}

A 39-week infant girl, born with VACTERL syndrome, was initially diagnosed with a long-gap pure esophageal atresia due to inability to pass a nasogastric tube and a gasless abdomen on abdominal radiograph. Shortly after birth, the patient underwent a gastrostomy tube placement and end colostomy for imperforate anus. Two months later, she underwent a right-sided thoracotomy, where a Type C TEF was encountered, as opposed to a pure esophageal atresia. She underwent ligation of the distal fistula, resection of a nonpatent fibrous cord of the distal esophageal limb with subsequent anastomosis of the esophageal limbs under tension. A postoperative esophagram revealed an anastomotic leak, which eventually resolved. Four months postoperatively, she underwent a follow-up esophagram which revealed a tight stricture at the anastomosis (-Fig. 1a). She underwent endoscopic balloon dilatation with fluoroscopic guidance every month for four consecutive months with persistence of the stricture at the anastomosis and no improvement.

At 10 months of age, the patient underwent a fourth endoscopic and fluoroscopic guided balloon dilatation of the stricture as before. After adequately dilating the stricture and visualizing circumferential, superficial linear disruption of the strictured ring at the anastomosis, we soaked $1 / 2$ inch $\times 1 / 2$-inch cottonoids in MMC solution $(0.4 \mathrm{mg} / \mathrm{mL})$. A rigid esophagoscope was utilized to apply the MMC-soaked cottonoid onto the left side of the stricture for a 1-minute time period followed by the placement of another MMC-soaked cottonoid on the right side of the stricture for 1 minute received

December 4, 2012

accepted after revision

January 16, 2013

published online

March 19, 2013 (c) 2013 Georg Thieme Verlag KG Stuttgart · New York
DOI http://dx.doi.org/ $10.1055 / \mathrm{s}-0033-1341418$. ISSN 2194-7619. 

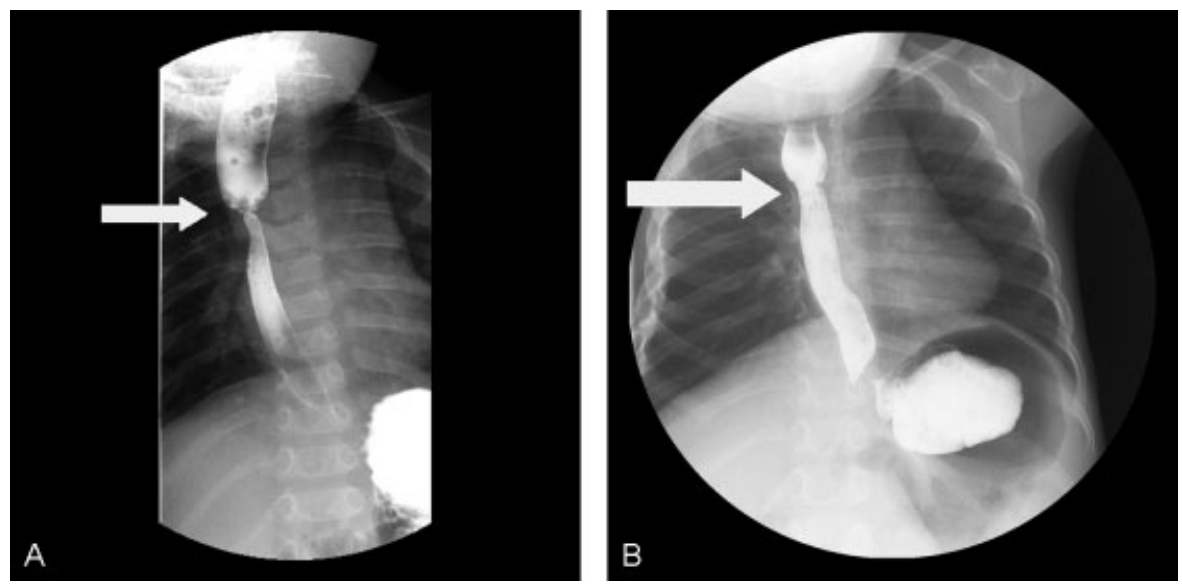

Fig. 1 (a) Esophagram of a tight stricture (white arrow) at the anastomosis in a 39-week-old infant girl, born with VACTERL syndrome. (b) Esophagram showing resolution (white arrow) of the esophageal stricture after balloon dilatation and treatment with mitomycin C.

(- Fig. 2). The cottonoids were removed, and the esophagus appeared intact. Follow-up surveillance endoscopy was performed after MMC application, which showed no evidence of an anastomotic stricture ( - Fig. 1 b). No additional balloon dilatation was required thereafter, and no recurrence of her stricture has since occurred. Now at 3 years of age, she remains asymptomatic, eats regular food after gastrostomy tube removal, and has not required further treatment.

\section{Case 2}

A 31-week twin infant girl underwent repair of a Type C TEF. Before thoracotomy, the patient's clinical condition deteriorated with marked distention of her abdomen. An open gastrostomy was first performed and placed to water seal, and a thoracotomy with ligation of a distal TEF and esophagoesophagostomy was performed under moderate tension. One month later, she developed symptoms of feeding intolerance, reflux, and tracheal aspiration. A repeat esophagram demonstrated a near-obstructing stricture in the midesophagus. The stricture was short, circumferential, and located at the site of the anastomosis. She was taken to the operating room for endoscopic balloon dilatation with fluoroscopic guidance, and subsequently underwent three more monthly balloon dilatations; however, there was no interval improvement in the stricture.
At 5 months of age, MMC was applied during the fifth esophageal dilatation in the same manner as described above. The patient underwent a follow-up surveillance endoscopy, which demonstrated no evidence of residual stricture. Two and a half years after the sole MMC application and dilatation, she remains asymptomatic.

\section{Discussion}

Esophageal stricture after TEF repair can develop when anastomoses are performed under vascular compromise or when esophageal limbs are joined under tension. ${ }^{4}$ Recurrent strictures may occur in patients with a predisposition for intense fibrinogenesis during anastomotic healing or as a wound healing response after esophageal dilatation treatment. ${ }^{5}$ Based on this model, MMC may be an ideal treatment to break the cycle of fibrosis and recurrent stricture formation.

MMC is an antineoplastic agent isolated from Streptomyces caespitosus, which can reduce scar formation by suppression of fibroblast proliferation and fibroblastic collagen synthesis via inhibition of DNA-dependent RNA synthesis. ${ }^{6}$ The antifibroblast properties of MMC have been applied to limit scar formation. ${ }^{7,8}$ A review of 31 pediatric patients of refractory esophageal strictures due to a variety of etiologies treated

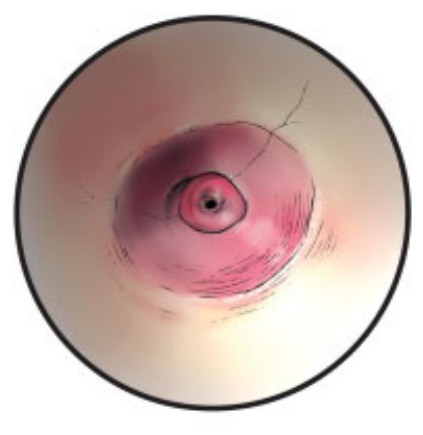

Stricture

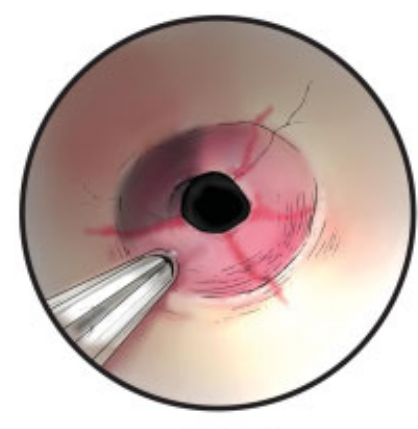

Dilated

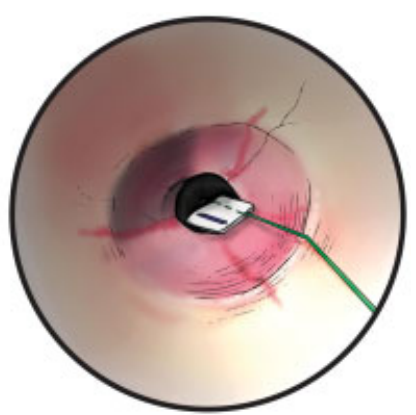

Treated

Fig. 2 Illustration of an endoscopic view of an esophageal stricture dilated by balloon and treated with a cottonoid soaked in mitomycin C. (Illustration by Scott Holmes, reprinted with permission from Baylor College of Medicine, Houston, Texas, United States.) 
Table 1 Literature review of mitomycin C (MMC) used for esophageal strictures following surgical repair in the neonatal period for variants of tracheoesophageal fistula (TEF) with esophageal atresia

\begin{tabular}{|c|c|c|c|c|c|c|}
\hline Author and year & $\begin{array}{l}\text { TEF } \\
\text { classification }\end{array}$ & Stricture description & $\begin{array}{l}\text { Number of } \\
\text { dilatations } \\
\text { before MMC } \\
\text { application }\end{array}$ & $\begin{array}{l}\text { Number of MMC } \\
\text { applications }\end{array}$ & $\begin{array}{l}\text { Time of } \\
\text { follow-up }\end{array}$ & Outcome \\
\hline Uhlen et al (2006) & Type A & $<4 \mathrm{~cm}$, short stenosis & 7 & 1 & $19 \mathrm{mo}$ & Asymptomatic \\
\hline Uhlen et al (2006) & Type A & $<4 \mathrm{~cm}$, short stenosis & 4 & 1 & $21 \mathrm{mo}$ & Asymptomatic \\
\hline Rosseneu et al (2007) & Type C & $10 \mathrm{~mm}$ stenosis & 3 & 1 & $\mathrm{~N} / \mathrm{A}$ & "Success" \\
\hline Rosseneu et al (2007) & Type C & $8-10 \mathrm{~mm}$ in length & 102 & 2 & $\mathrm{~N} / \mathrm{A}$ & "No success" \\
\hline Heran et al (2011) & Type C & N/A & 8 & 1 & $19 \mathrm{mo}$ & Asymptomatic \\
\hline Lakoma et al (present study) & Type C & Short, circumferential & 3 & 1 & $2 y$ & Asymptomatic \\
\hline Lakoma et al (present study) & Type C & Short, circumferential & 4 & 1 & $2 y$ & Asymptomatic \\
\hline
\end{tabular}

Abbreviation: N/A, not available.

with MMC reports an $87.7 \%$ rate of improvement in symptoms. $^{2}$

With regards to MMC use for esophageal strictures, there have been only five previously reported cases following surgical repair in the neonatal period for variants of TEF with esophageal atresia: three after Type C TEF repair and two after pure esophageal atresia repair ( - Table 1). ${ }^{9,10}$ Of these reported cases, the authors attributed the refractory esophageal stricture to concomitant reflux in three cases and to a repair performed under tension in one case. In four of the five cases reported, three to eight esophageal dilatations were performed before the application of MMC. All had successful resolution of the strictures without procedural complications. Similarly, our patients likely formed strictures due to repair performed under tension. We recommend the prompt addition of MMC after a moderate amount of dilatations with the rationale to break the proposed cycle of fibrinogenesis and refractory stricture formation.

Initial reports of the use of MMC demonstrate a good safety profile. However, one study of six pediatric patients with refractory esophageal stenosis discovered evidence of de novo gastric metaplasia on follow-up esophageal biopsy in two patients. ${ }^{11}$ Furthermore, MMC can be absorbed mucosally causing systemic side effects, which include bone marrow suppression and hypersensitivity reactions. ${ }^{12}$ The majority of the literature describes the procedure as being safe without adverse effects. ${ }^{2,9}$

\section{Conclusion}

This case report supports the utility and safety of MMC treatment as an adjunct to endoscopic balloon dilatation in managing refractory esophageal strictures following TEF repair. Despite multiple failed esophageal dilatation attempts, our two patients have remained asymptomatic and stricturefree over 2 years after a single application of MMC, potentially saving these children from additional procedures.
Conflict of Interest

None

\section{References}

1 Engum SA, Grosfeld JL, West KW, Rescorla FJ. Analysis of morbidity and mortality in 227 cases of esophageal atresia and/ or tracheoesophageal fistula over two decades. Arch Surg 1995;130(5):502-508, discussion 508-509

2 Berger M, Ure B, Lacher M. Mitomycin C in the therapy of recurrent esophageal strictures: hype or hope? Eur J Pediatr Surg 2012;22(2):109-116

3 Olutoye OO, Shulman RJ, Cotton RT. Mitomycin C in the management of pediatric caustic esophageal strictures: a case report. J Pediatr Surg 2006;41(5):e1-e3

4 Kovesi T, Rubin S. Long-term complications of congenital esophageal atresia and/or tracheoesophageal fistula. Chest 2004; 126(3):915-925

5 Uhlen S, Fayoux P, Vachin F, et al. Mitomycin C: an alternative conservative treatment for refractory esophageal stricture in children? . Endoscopy 2006;38(4):404-407

6 Türkyilmaz Z, Sönmez K, Demirtola A, et al. Mitomycin C prevents strictures in caustic esophageal burns in rats. J Surg Res 2005; 123(2):182-187

7 Holló G. Wound healing and glaucoma surgery: modulating the scarring process with conventional antimetabolites and new molecules. Dev Ophthalmol 2012;50:79-89

8 Shridharani SM, Magarakis M, Manson PN, Singh NK, Basdag B, Rosson GD. The emerging role of antineoplastic agents in the treatment of keloids and hypertrophic scars: a review. Ann Plast Surg 2010;64(3):355-361

9 Rosseneu S, Afzal N, Yerushalmi B, et al. Topical application of mitomycin- $\mathrm{C}$ in oesophageal strictures. J Pediatr Gastroenterol Nutr 2007;44(3):336-341

10 Heran MK, Pham TH, Butterworth S, Robinson A. Use of a microporous polytetrafluoroethylene catheter balloon to treat refractory esophageal stricture: a novel technique for delivery of mitomycin C. J Pediatr Surg 2011;46(4):776-779

11 Michaud L, Gottrand F. Anastomotic strictures: conservative treatment. J Pediatr Gastroenterol Nutr 2011;52(Suppl 1):S18-S19

12 Heran MK, Baird R, Blair GK, Skarsgard ED. Topical mitomycin-C for recalcitrant esophageal strictures: a novel endoscopic/fluoroscopic technique for safe endoluminal delivery. J Pediatr Surg 2008;43(5):815-818 